\title{
Prevalence of Workplace Bullying and Its Associated Factors among Workers in a Malaysian Public University Hospital: A Cross-Sectional Study
}

This article was published in the following Dove Press journal: Risk Management and Healthcare Policy

\author{
Nur Syakirah Awai (iD) ${ }^{1,2}$ \\ Kurubaran Ganasegeran (D) ${ }^{3}$ \\ Mohd Rizal Abdul Manaf (D) \\ 'Department of Community Health, \\ Faculty of Medicine, Universiti \\ Kebangsaan Malaysia, Kuala Lumpur \\ 56000, Malaysia; ${ }^{2}$ Family Health \\ Development Division, Ministry of Health \\ Malaysia, Putrajaya 62590, Malaysia; \\ ${ }^{3}$ Clinical Research Center, Seberang Jaya \\ Hospital, Ministry of Health Malaysia, \\ Penang 13700, Malaysia
}

Background and Purpose: Workplace bullying has been regarded as a serious phenomenon, particularly in health-care settings, due to its tendency to predispose health workers to serious psychological repercussions, job dissatisfaction, and turnover. Such consequences are costly to health systems and disruptive to the continuity of patient care. While global bullying literature in health settings grows, evidence on the magnitude of the problem from a Malaysian perspective is scarce. This study aimed to determine the prevalence of workplace bullying and its associated factors among health workers in a Malaysian public university hospital.

Methods: This cross-sectional study was conducted from October to December 2019 among 178 hospital workers at the Hospital Canselor Tuanku Muhriz in Kuala Lumpur, Malaysia. The study utilized a self-administered questionnaire that consisted of items on sociodemographics, work characteristics, sources of bullying, and the validated Malay version of the 23-item Negative Acts Questionnaire - revised to determine the prevalence of bullying. Descriptive and inferential statistics were analyzed using SPSS 22.0. Statistical significance was set at $P<0.05$.

Results: The prevalence of workplace bullying in this sample was $11.2 \%$. Superiors or supervisors from other departments and colleagues were the main perpetrators. In the multivariate model, working for 10 years or less (aOR 4, 95\% CI $1.3-12.3 ; P=0.014$ ) and not being involved in patient care (aOR 5, 95\% CI 2.5-10; $P<0.001$ ) were statistically significant attributes associated with workplace bullying.

Conclusion: Workplace bullying in the current study was strongly associated with occupational characteristics, particularly length of service and service orientation of the workers. Hospital directors and managers could undertake preventive measures to identify groups vulnerable to bullying and subsequently craft appropriate coping strategies and mentoring programs to curb bullying.

Keywords: bullying, health care, negative acts, vulnerable populations, workplace

\section{Introduction}

Bullying has been conceptualized as systematic exposure to humiliation, hostile, aggressive behavior, and unethical, oppressive communication against an individual or group at least once a week for at least 6 months. ${ }^{1-3}$ While primitive records of bullying behavior exist from childhood studies, ${ }^{4}$ scholarly works in the late 1980s shifted focus to investigate adult bullying within the context of the workplace environment as a consequence of rapid industrialization. ${ }^{1}$ The exponential growth in bullying literature in various occupations have characterized such negative acts as
Correspondence: Mohd Rizal Abdu Manaf

Department of Community Health, Faculty of Medicine, Universiti Kebangsaan Malaysia, Kuala Lumpur 56000, Malaysia

Email mrizal@ppukm.ukm.edu.my

Risk Management and Healthcare Policy 202I:14 75-85 
a universal threat to contemporary working life, ${ }^{5}$ with debilitating effects on both individuals and organizations. ${ }^{6,7}$ Across occupational settings, the exploration of workplace bullying in the field of medicine and health care is relatively new. However, evidence from studies that have evaluated the bullying phenomenon within the health-care workforce has pointed to serious consequences to health workers, patients, and relevant stakeholders. ${ }^{8,9}$

The antecedents of workplace bullying are complex to apprehend. They have been attributed to the hierarchical model of organizational climate that labels bullying as "acceptable", but "unpleasant". ${ }^{10}$ Factors escalating bullying incidence include stressful and demanding work environments, competitive and unsupportive colleagues, and normalization of impoliteness in common conduct. ${ }^{11-13}$ Workplace bullying in hospitals or health-care institutions has been known to escalate burnout incidence, serious psychological repercussions like depression, anxiety, or stress, job dissatisfaction, and turnover among hospital workers. ${ }^{14-16}$ Specifically, doctors being bullied are more prone to make medical errors, ${ }^{17}$ while bullied nurses demonstrate poor job performance, affecting continuity of patient care. ${ }^{8,18}$ Coupled with high absenteeism, turnover, and decreased productivity within health-care settings, these consequences result in substantial costs at the organizational level. ${ }^{19}$ It is noteworthy that emerging research has postulated that the bullying phenomenon in health care should encompass all workers within the hospital setting, including clinical support and administrative staff, in view of the organizational power structure that requires interrelated departments' commitment to the continuity of health management and care. ${ }^{20}$

With definitions of workplace bullying varying across populations, a range of tools have been developed to determine the prevalence and determinants of bullying. These measurement tools were developed and validated across different regions, cultures, and geographical settings, leading to varying prevalence across countries and populations being studied. This has led to inconsistent estimates of the magnitude of bullying in occupational settings. A review from European countries reported that prevalence of workplace bullying in health care was $0.3 \%-85.5 \%$.

Multiple factors have been connected to bullying. These include female workers, young age, novice workers, work pressures and demands, shift-work rotations, and stress. $^{7,9,21-23}$ While such evidence is plentiful in Western settings, evidence of workplace bullying across health-care settings are relatively scarce in Eastern, Asian, and developing countries.

From the Malaysian perspective, studies have attempted to explore bullying in the workplace in the non-healthcare ${ }^{24,25}$ and health-care domains. ${ }^{26-28}$ These works have provided useful insights to further explore the magnitude of workplace bullying, particularly from health workers' perspectives, given the escalated burden faced in modern medical practice for greater commitment to service delivery and organizational structure. Given these circumstances and Malaysia's high power distanceindex score (104 out of 120), ${ }^{29}$ the current study aimed to determine the prevalence of workplace bullying and its associated factors among health workers in a Malaysian public university hospital.

\section{Methods}

\section{Study Design, Setting, and Population}

This cross-sectional single-center study was conducted from October to December 2019 among workers at the Hospital Canselor Tuanku Muhriz, a public tertiary teaching hospital integrated with the Universiti Kebangsaan Malaysia (UKM) to provide training and health services in the city of Kuala Lumpur. Sample recruitment included clinical, clinical support, and administrative staff of the hospital who had worked $>6$ months in the same department. Workers on study or maternity leave and contract workers were excluded.

\section{Sample Size}

The sample size was calculated based on the formula advocated by $\mathrm{Kish}^{30}$ for prevalence studies:

$$
n=\left(Z_{1-\alpha}\right)^{2}\left[P \frac{1-P}{D^{2}}\right]
$$

where

$n$ is the size of the calculated sample from the population,

$Z_{1-\alpha}=1.96(95 \% \mathrm{CI}$, value from the normal-distribution table),

$P$ is prevalence, and

$D$ is absolute precision.

Based on prevalence of $11.3 \%$ for workplace bullying from a previous study, ${ }^{31,32}$ with a precision of $5 \%$ and CI (1- $\alpha$ ) set at $95 \%$, the minimum sample size required to calculate the prevalence of workplace bullying in this 
study was 154 . We added $20 \%$ to the calculated sample size to compensate for non response, and thus our final sample was 185 respondents.

\section{Ethics Statement}

This study complied with the guidelines convened in the Declaration of Helsinki. Ethics approval was obtained from the UKMMC Institutional Ethics Committee (UKM PPI/111/8/JEP-2019-291). Study objectives and benefits were explained verbally and in written form attached to the questionnaires. Respondents' confidentiality and anonymity were assured, with written consent obtained from those who agreed to participate.

\section{Study Instrument}

A self-administered questionnaire consisting of four parts was utilized in this study. The first part consisted of five items on sociodemographic characteristics: sex, age, ethnicity, marital status, and education.

The second part included items on work characteristics, such as field of current practice, length of service, service orientation, working hours per week, and shift-work rotation. Field of current practice was categorized into administrative services (customer service and quality), clinical services (internal medicine, emergency medicine, general surgery, orthopedics, anesthesiology, obstetrics and gynecology, and radiology), and clinical support services (pharmacy, diagnostic laboratory services, dietetic and food services, and medical rehabilitation). Service orientation was categorized into workers involved in patient care (nurses, medical officers, specialists, consultants, pharmacists, therapists, radiographers, dietitians, and medical laboratory technicians) and workers not involved in patient care (attendants, clerks, and other support staff).

The primary outcome measure, workplace bullying, was evaluated in the third part. This study adopted a recommended method of measuring the prevalence of workplace bullying and specific negative acts through an objective approach and a self-labeled definition of bullying. ${ }^{33}$ The validated 23-item Negative Acts Questionnaire - revised (NAQ-r), ${ }^{34}$ which measures the prevalence of a range of 22 potentially bullying acts and overall bullying prevalence was utilized. The NAQ-r has been developed and validated in many countries, ${ }^{33,35,36}$ including Malaysia. ${ }^{37}$ Respondents were asked to rate how often they had experienced each negative act in the workplace within the past 6 months using a five-point Likert scale (1 never, 2 now and then, 3 monthly, 4 weekly and 5 daily). The
NAQ-r provides prevalence rates for each of the 22 negative acts and an overall score, from 22 (never experienced any of the 22 negative acts) and 110 (experience all 22 negative acts on a daily basis). The scale has specific subdomains scores, particularly work-related negative acts, with possible scores of 7-35 (comprised of items 1, 3, 14, 16, 18, 19, and 21), person-related negative acts domain that scores between 12 and 60 (comprised of items 2, 4, 5, 6, 7, 10, 11, 12, 13, 15, 17, and 20) and physical intimidating acts, with possible scores of 3-15 (comprised of items 8,9 , and 22). ${ }^{38}$

To determine the prevalence of workplace bullying in this sample, an operational criterion suggested by Mikkelsen and Einarsen ${ }^{39}$ was added to the NAQ-r: a person is considered a victim of bullying if he or she has been exposed to at least two negatively defined acts four or five times (weekly or daily) in the past 6 months. In addition to the 22 NAQ-r items, it also includes an overall self-labeling measure of perceived workplace bullying (item 23). Participants were provided with a definition of bullying advocated by Einarsen et al. ${ }^{34}$ a situation where one or several individuals persistently perceive themselves to be on the receiving end of negative actions from one or several persons where the target of bullying has difficulty in defending himself or herself against these actions. A one-off incident will not be referred as bullying. Subjects were asked, "Have you been bullied by other staff at work over the last 6 months?", with a five response options (no; yes, but only rarely; yes, now and then; yes, several times per week; and yes, almost daily). ${ }^{8}$

The final part assessed respondents' self-labeled sources of bullying in the workplace. Five items that identified the most common perpetrators among victims of bullying were listed (immediate superiors or supervisors, other superiors or supervisors within the organization, colleagues, subordinates, and clients/patients). Item responses were dichotomized as yes or no.

\section{Validity and Reliability}

The validated Malay version of the NAQ-r was used in this study. Cronbach's $\alpha$ value for the NAQ-r scale administered in this sample was 0.954, suggesting excellent internal consistency. Prior to administration of the questionnaire, face and content validity were assessed by two independent public health researchers on the suitability and comprehensibilty of the items. Subsequently, the questionnaire was piloted among 20 hospital workers who were not respondents in this study to assess its 
comprehensibility and ease of completion. No significant changes were made during the validity or pilot phase.

\section{Data Collection}

The questionnaire was administered during the hospital's weekly continuous medical education (CME) session using consecutive sampling. Due to its sensitivity, the questionnaire was given to the respondents in a sealed envelope. Respondents were given the envelopes at the beginning of the CME registration, and these were collected at the end of the session.

\section{Statistical Analyses}

Data collected were analyzed using SPSS 22.0. Descriptive statistics were used for all variables. Binary logistic regression and $\chi^{2}$ were used to assess associations between workplace bullying and categorical independent variables in this study. Multiple logistic regression analysis using backward regression was employed to determine the most parsimonious model on factors determining workplace bullying. Multicollinearity between independent variables was checked for a variation inflation factor $\leq 10$. Statistical significance was set at $P<0.05$.

\section{Results}

\section{Sample Characteristics}

A total of 185 consecutive hospital workers were invited to participate in this study, and $178(96.2 \%)$ participated. The sample constituted 117 (65.7\%) women and 61 (34.3\%) men. The majority of the respondents were $>30$ years of age $(88.2 \%)$. Most respondents were Malay (83.7\%), married $(86.5 \%)$, and tertiary-educated $(82 \%)$. The bulk of them were working in clinical services $(65.7 \%)$ and with $\leq 10$ years' experience $(50.6 \%)$. Most respondents worked mostly in patient care (73.6\%). The majority worked $\geq 40$ hours a week (83.1\%) and did not work on shifts $(52.8 \%$, Table 1).

\section{Negative Acts Encountered among Respondents}

The overall mean \pm SD NAQ-r score was $31.9 \pm 11.6$, with a range of 22-100. Analysis of NAQ-r subscales revealed that mean scores was the highest for negative personrelated acts $(17.2 \pm 6.5)$, followed by negative workplacerelated acts $(10.9 \pm 4.5)$ and negative physical/intimidating acts $(3.8 \pm 1.4)$.
Table I Sample Characteristics $(n=178)$

\begin{tabular}{|c|c|}
\hline Demographics & n (\%) \\
\hline \multicolumn{2}{|l|}{ Sex } \\
\hline Men & 6I (34.3) \\
\hline Women & $117(65.7)$ \\
\hline \multicolumn{2}{|l|}{ Age (years) } \\
\hline $18-30$ & $21(11.8)$ \\
\hline$>30$ & $157(88.2)$ \\
\hline \multicolumn{2}{|l|}{ Ethnicity } \\
\hline Malay & 149 (83.7) \\
\hline Non-Malay* & $29(16.3)$ \\
\hline \multicolumn{2}{|l|}{ Marital status } \\
\hline Married & $154(86.5)$ \\
\hline Single & 24 (I3.5) \\
\hline \multicolumn{2}{|l|}{ Education } \\
\hline Secondary & $32(18.0)$ \\
\hline Tertiary & $146(82.0)$ \\
\hline \multicolumn{2}{|l|}{ Work characteristics } \\
\hline \multicolumn{2}{|l|}{ Current practice } \\
\hline Administrative services & $18(10.1)$ \\
\hline Clinical services & $117(65.7)$ \\
\hline Clinical support services & $43(24.2)$ \\
\hline \multicolumn{2}{|l|}{ Length of service (years) } \\
\hline$\leq 10$ & $90(50.6)$ \\
\hline$>10$ & $88(49.4)$ \\
\hline \multicolumn{2}{|l|}{ Service orientation } \\
\hline Involved in patient care & $|3|(73.6)$ \\
\hline Not involved in patient care & $47(26.4)$ \\
\hline \multicolumn{2}{|l|}{ Work hours per week } \\
\hline$<40$ & $30(16.9)$ \\
\hline$\geq 40$ & I48 (83.1) \\
\hline \multicolumn{2}{|l|}{ Shift work } \\
\hline Yes & $84(47.2)$ \\
\hline No & $94(52.8)$ \\
\hline \multicolumn{2}{|l|}{ Workplace bullying (based on NAQ-r) } \\
\hline Yes & $20(11.2)$ \\
\hline No & $158(88.8)$ \\
\hline
\end{tabular}

Notes: *Included Chinese, Indian, and “Others”.

The most prevalent negative person-related act on a daily or weekly basis was the spreading of gossip and rumors (3.9\%). The most common negative workplace-related act on a daily or weekly basis was being ordered to work below one's competence level (5.6\%). Being shouted at or being the target of spontaneous anger on a weekly or daily basis was the most frequently experienced negative physical/intimidating act (5.6\%). Figure 1 exhibits detailed prevalence for all 22 NAQ-r items. 


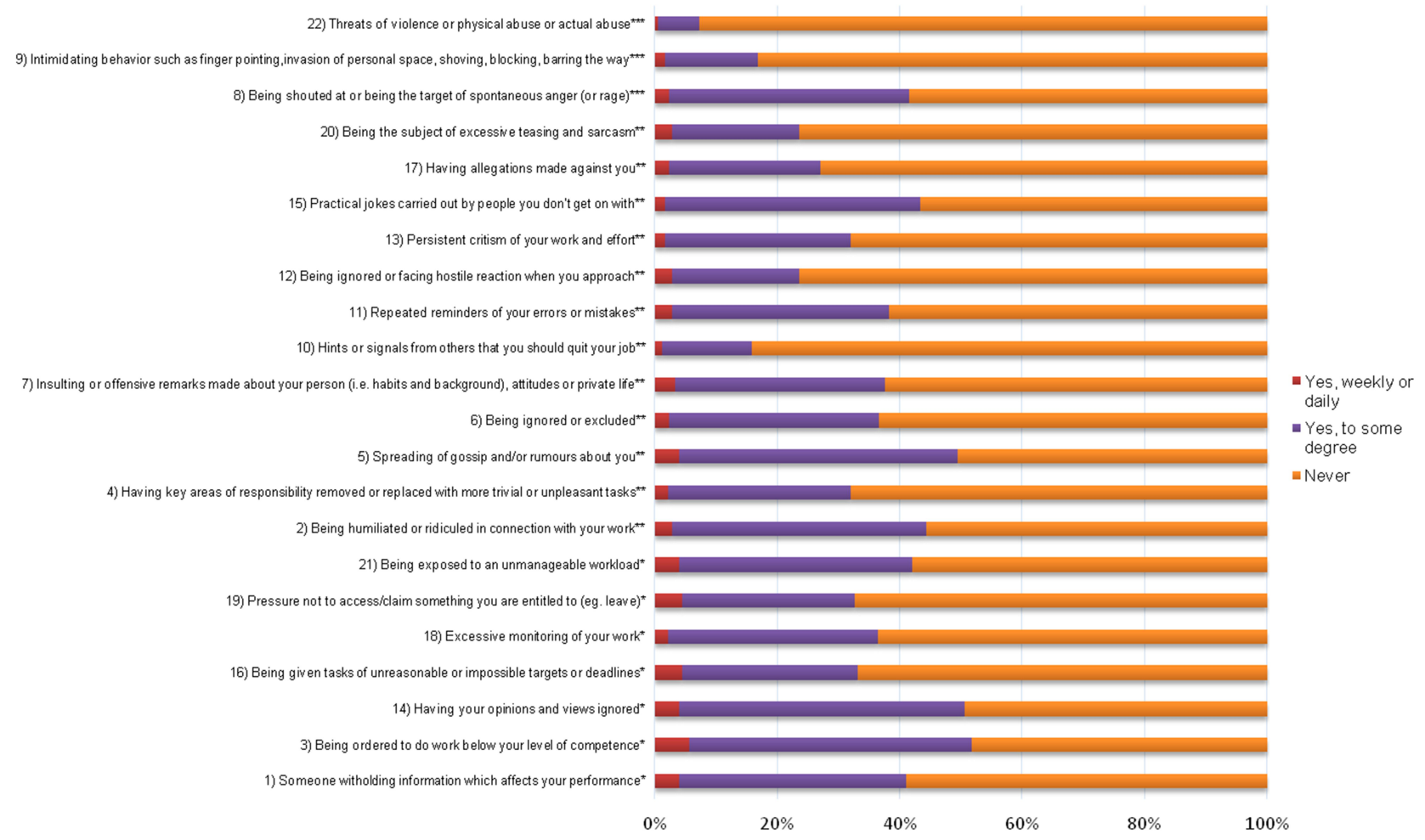

Figure I Percentage of respondents who encountered negative behavior over the past 6 months based on the NAQ-r ( $n=178)$.

Notes: *Work-related bullying; **person-related bullying; ***physical, intimidating bullying. Red indicates response options for "weekly" and "daily", collapsed as "yes, weekly or daily"; purple indicates item-response options of "now and then" and "monthly", collapsed as "yes, to some degree"; orange indicates "never".

\section{Prevalence of Workplace Bullying According to Self-Labeling and NAQ-r}

Self-labeling as a victim of bullying was present for 41 of the 178 respondents (23\%), while $137(77.0 \%)$ did not refer to being bullied. In sum, 38 respondents (21.4\%) self-labeled as being a victim of bully at least once in the past 6 months, and only three (1.7\%) selflabeled as a bullied victim on a daily or weekly basis in the past 6 months. The prevalence of workplace bullying over the past 6 months according to operational definitions applied to the NAQ- $r$ in this sample was $11.2 \%$.

\section{Common Perpetrators}

Of the 20 respondents who self-labeled as being bullied, the most commonly cited perpetrators were other departmental superiors or supervisors within the organization $(14.0 \%)$, followed by colleagues $(12.4 \%)$ and immediate superiors or supervisors $(6.2 \%$, Figure 2). Common perpetrators were women $(44.4 \%)$.

\section{Association Between Sample Characteristics and Workplace Bullying Measured by NAQ-r}

Workers aged 18-30 years had about fourfold the odds of workers aged $>30$ years of being bullied (OR $4.1,95 \%$ CI $1.4-12.2 ; P=0.007)$. Those working $\leq 10$ years had threefold the odds of those working $>10$ years of being bullied (OR $3.3,95 \%$ CI $1.2-9.5 ; P=0.02$ ). Workers not involved in patient care had about fivefold the odds of workers involved in patient care of being bullied (OR 5.3, 95\% CI 2-13.8; $P<0.001)$. Respondents working $<40$ hours per week had triple the odds of respondents working $\geq 40$ hours of being bullied (OR 3.2, 95\% CI 1.4-8.7; $P=0.021$, Table 2).

\section{Factors Associated with Workplace Bullying Measured by NAQ-r using Multiple Logistic Regression (Backward Wald) Analysis}

All statistically significant variables associated with workplace bullying on univariate analysis were included in the multivariate analysis. The final regression model retained 


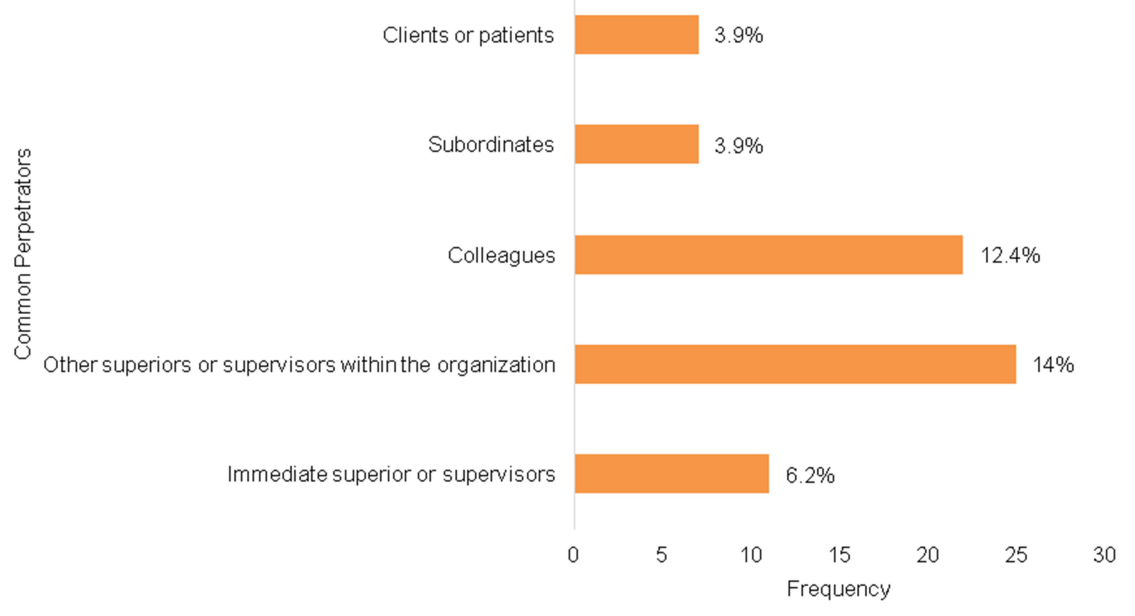

Figure 2 Common perpetrators reported by respondents being bullied $(n=72)$. Note: Bullied respondents were able to report more than one perpetrator.

two statistically significant factors associated with workplace bullying: working $\leq 10$ years (aOR 4, 95\% CI $1.3-$ 12.3; $P=0.014$ ) and not being involved in patient care (aOR 5, 95\% CI 2.5-10; $P<0.001$ ). The total model was significant $(P<0.001)$ and accounted for $20 \%$ of the variance. There was no multicollinearity between independent variables (Table 3).

\section{Discussion}

This study aimed to determine the prevalence of workplace bullying and its associated factors among health workers in a Malaysian public university hospital. Variation in prevalence of workplace bullying exists in the scholarly literature. Self-labeling as being a victim of bullying in this study was $1.7 \%$. The prevalence of workplace bullying among hospital workers according to the NAQ-r was $11.2 \%$. In the Western literature, the selflabeling prevalence of bullying in this study was lower than results reported in European and Spanish healthworkers survey ${ }^{21,31}$ and Finnish, Norwegian, and Austrian samples, with prevalence rates of 3\%-8\%. ${ }^{14,40-44}$ The prevalence of bullying reported using the NAQ-r in the current study was much lower than that found in UK National Health Service staff $(20 \%){ }^{8}$ doctors and nurses working in neonatal intensive care units in Greece (approximately 53\% each), ${ }^{9}$ and the medical workforce in New Zealand (38\%), ${ }^{38}$ but higher than health-care workers in Portugal (8\%). ${ }^{33}$ In Eastern and Asian settings, the prevalence of workplace bullying among health workers in Saudi Arabia and India was approximately 50\%, while bullying among health workers in Thailand was
$38.8 \%$ using self-labeling. ${ }^{45-47}$ Health workers in China and Japan reported prevalence rates using the NAQ-r of $5.6 \%-18.5 \%{ }^{48,49}$ A recent investigation from Malaysia found that $13 \%$ of junior doctors reported bullying in the workplace using the NAQ-r. ${ }^{28}$

The reported prevalence of workplace bullying in this study was inconsistent with other studies. It was found that self-labeling prevalence as being a victim of bully (approximately 1.7\%) was lower than that of an operational definition conceptualized by Mikkelsen and Einarsen $^{39}$ of the NAQ-r score (11.2\%). Plausible explanations for this could be conceptualization of methodological approaches, such as study tools being utilized or how bullying was operationalized. ${ }^{50}$ Two other methods have been used to operationalize the prevalence of bullying. The first is a self-labeling definition that measures an individual's subjective experiences of being victimized in the workplace. This method assesses respondents' perceptions using a single-item question on whether they have been bullied or not, ${ }^{33,50}$ but in some studies the definition of bullying has been conceptualized as respondents prior to being asked whether they had been a victim of bully. $^{42,51}$ This approach utilizes an arbitrary criterion that provides unstable estimates on prevalence rates of the outcome being studied. ${ }^{33,52}$ The second method was to apply a behavioral experience technique, ${ }^{52}$ which administers an inventory of various negative acts (NAQr) to respondents and requests that they indicate how often they have been exposed to each negative act during the previous 6-12 months. This method offers more reliable results, but these may be influenced by a variety of cutoffs 
Table 2 Associations between Sample Characteristics and Workplace Bullying Based on the NAQ-r $(n=178)$

\begin{tabular}{|c|c|c|c|c|c|}
\hline & \multicolumn{2}{|c|}{ Workplace Bullying } & \multirow[t]{2}{*}{ OR } & \multirow[t]{2}{*}{$95 \% \mathrm{Cl}$} & \multirow[t]{2}{*}{$P$-value } \\
\hline & Yes, n (\%) & No, n (\%) & & & \\
\hline \multicolumn{6}{|l|}{ Demographics } \\
\hline \multicolumn{6}{|l|}{ Sex } \\
\hline Men & $5(8.2)$ & $56(91.8)$ & I & & \\
\hline Women & $15(12.8)$ & $102(87.2)$ & 1.7 & $0.6-4.8$ & 0.358 \\
\hline \multicolumn{6}{|l|}{ Age (years) } \\
\hline $18-30$ & $6(28.6)$ & $15(7 \mid .4)$ & 4.1 & $1.4-12.2$ & 0.007 \\
\hline$>30$ & $14(8.9)$ & $143(91.1)$ & 1 & & \\
\hline \multicolumn{6}{|l|}{ Ethnicity } \\
\hline Malay & $18(12.1)$ & $|3|(87.9)$ & 1.9 & $0.4-8.5$ & 0.419 \\
\hline Non-Malay & $2(6.9)$ & $27(93.1)$ & I & & \\
\hline \multicolumn{6}{|l|}{ Marital status } \\
\hline Married & $16(10.4)$ & $138(89.6)$ & I & & \\
\hline Single & $4(16.7)$ & $20(83.3)$ & 1.7 & $0.5-5.7$ & 0.365 \\
\hline \multicolumn{6}{|l|}{ Education } \\
\hline Secondary & $6(18.8)$ & $26(8 \mathrm{I} .2)$ & 2.2 & $0.8-6.2$ & 0.137 \\
\hline Tertiary & $14(9.6)$ & $132(90.4)$ & I & & \\
\hline \multicolumn{6}{|l|}{ Work characteristics } \\
\hline \multicolumn{6}{|l|}{ Current practice } \\
\hline Administrative services & $2(I I . I)$ & $16(88.9)$ & 1.3 & $0.2-10$ & 0.829 \\
\hline Clinical services & $14(12.0)$ & $103(88.0)$ & 1.3 & $0.4-5$ & 0.637 \\
\hline Clinical support services & $4(9.3)$ & $39(90.7)$ & I & & \\
\hline \multicolumn{6}{|l|}{ Length of service (years) } \\
\hline$\leq 10$ & $15(16.7)$ & $75(83.3)$ & 3.3 & $1.2-9.5$ & 0.02 \\
\hline$>10$ & $5(5.7)$ & $83(94.3)$ & I & & \\
\hline \multicolumn{6}{|l|}{ Service orientation } \\
\hline Involved in patient care & $8(6.1)$ & $123(93.9)$ & I & & \\
\hline Not involved in patient care & $12(25.5)$ & $35(74.5)$ & 5.3 & $2-13.8$ & $<0.001$ \\
\hline \multicolumn{6}{|l|}{ Work hours per week } \\
\hline$<40$ & $7(23.3)$ & $23(76.7)$ & 3.2 & I.4-8.7 & 0.021 \\
\hline$\geq 40$ & $13(8.8)$ & $135(91.2)$ & I & & \\
\hline \multicolumn{6}{|l|}{ Shift work } \\
\hline Yes & $7(8.3)$ & 77 (91.7) & I & & \\
\hline No & $13(13.8)$ & $81(86.2)$ & 1.8 & $0.7-4.7$ & 0.246 \\
\hline
\end{tabular}

or scoring methods used to determine the prevalence of bullying, such as a cutoff score $\geq 33$ as being a victim of bully $^{9}$ or to apply such an operational definition as a person being considered a victim of bullying if he/she has been exposed to at least two negatively defined acts four or five times weekly or daily in the past 6 months. ${ }^{39}$ It has been postulated that studies employing either one of the methods will yield inflated prevalence rates, and hence researchers recommend using a combinatory method to yield better and more reliable estimates when conducting surveys. $^{33-39}$

A second plausible explanation for such variant prevalence rates could be societal culture, often seen as a proxy to workplace bullying. ${ }^{53,54}$ Such acceptance of workplace bullying as a cultural dimension widens power distances within the organizational climate, often seen in Eastern culture compared to Western countries. This acceptability is facilitated by Hofstede's cultural 
Table 3 Factors Associated with Workplace Bullying Based on the NAQ-r Using Multiple Logistic Regression Analysis (Backward Wald)

\begin{tabular}{|c|c|c|c|c|c|c|}
\hline & $\boldsymbol{\beta}$ & SE & Wald & $\operatorname{Exp}(\beta)$ & $95 \% \mathrm{Cl}$ & P-value \\
\hline \multicolumn{7}{|l|}{ Length of service (years) } \\
\hline$\leq 10$ & -1.4 & 0.6 & 6.1 & 4 & $1.3-12.3$ & 0.014 \\
\hline$>10$ & Ref & Ref & Ref & Ref & Ref & Ref \\
\hline \multicolumn{7}{|l|}{ Service orientation } \\
\hline Involved in patient care & Ref & Ref & Ref & Ref & Ref & Ref \\
\hline Not involved in patient care & -1.8 & 0.5 & 12.4 & 5 & $2.5-10$ & $<0.001$ \\
\hline
\end{tabular}

Notes: Variables entered include all significant variables in the univariate analysis. Exp ( $\beta$ ) gives the adjusted Odds Ratio (aOR).“Ref” indicates reference category.

framework, ${ }^{55}$ which advocates vital influence to estimate the prevalence of bullying. Based on this framework of power distance, employees at lower in the hierarchicy or subordinates often disregard bullying as a form of mistreatment and accept such negative acts as a workplace norm. Such acceptance leads to under reporting of prevalence. In contrast, Western cultures apprehends bullying as unacceptable and a chronic organizational stressor that needs to be reported to higher authorities, thus yielding probable escalated prevalence rates. ${ }^{56}$

The final regression model yielded two significant factors as highly associated with workplace bullying, namely hospital workers with experience $\leq 10$ years and those not involved in patient care. Workers with less experience were more likely to be bullied than senior ones. Similar associations have been observed in previous studies. ${ }^{48,57,58}$ Such vulnerability to bullying among junior staff could be caused by collapsed coping mechanisms for workplace stressors or the hierarchical structure within the organization that demands work beyond one's capabilities while trying to adapt to a new organizational climate. ${ }^{24,59}$ Similarly, workers who were not involved in patient care, such as administrative or clerical staff, were highly vulnerable to workplace bullying, and this finding was consistent with a previous study. ${ }^{33}$

Two variables - age and working hours per week though being statistically significant at the univariate level, were eliminated in the final regression model. This study found that younger workers were more likely to be bullied than senior ones. This finding was similar to results reported in Poland ${ }^{58}$ and the UK, ${ }^{15}$ but inconsistent with findings from Portugal ${ }^{33}$ and Spain. ${ }^{21}$

Those with longer working hours are often susceptible to greater work overload, which can increase one's sensitivity to bullying and increase exposure to violence and abuse. ${ }^{58,60,61}$ This logical apprehension was reversed in the current study, noting that hospital workers in this study who worked $<40$ hours per week reported greater susceptibility to bullying than those who worked $\geq 40$ hours per week. However, this can plausibly be explained through a string of observations via an anticipated triple-variable effect. Firstly, we noted that negative person-related acts scored more highly than negative workplace-related acts, thus catalyzing the assumption that work nature and organizational structure did not precipitate bullying. Secondly, staff not involved in patient care and those working $<40$ hours per week were more likely to be in administrative, clerical, nonclinical, or support roles and more inclined to office work, thus eliminating exposure to being overworked or instructed to work beyond one's capacity, which can lead to bullying. This suboccupational group within the hospital's organizational structure may be prone to laissez-faire leadership in which the leader of the organization makes limited decisions to allow their staff to choose appropriate workplace solutions through inter- or intra-departmental teamwork. This however may lead to "horizontal" workplace bullying, wherein perpetrators are superiors and supervisors from other departments or colleagues, as observed in the current study, which frequently occurs in such occupational groups due to competitive behavior to earn specific positions or promotions. ${ }^{33,35}$ The situational conceptualization occurring in this study could have been attributed to mediating or confounding effects of the variables studied, and was thus eliminated in the final regression model.

In a systematic review, Feijo et al. ${ }^{22}$ concluded that women were twice as likely as men to be bullied in the workplace. This can be explained by the positions of power that men and women occupy inside organizations, in which men more frequently acquire leadership positions. $^{62}$ However, we were able to disregard this assumption, as the majority of workers in this study were 
women who commonly reported perpetrators to be other women. Although the current study observed a higher likelihood of women being bullied, the relationship was not statistically significant. Ethnicity showed no statistical significance in workplace bullying in the current study, consistent with previous studies. ${ }^{8,38}$ While previous studies have found significant relationships between workplace bullying and marital status, ${ }^{22}$ education, ${ }^{21}$ and shiftwork rotations, ${ }^{21}$ this study found no such statistical associations.

The current study provides evidence for hospital directors and managers to undertake preventive actions to eliminate workplace bullying. Preventive measures could be introduced at hospital, departmental, or unit levels to recognize vulnerable groups with the highest risk of exposure to bullying. Mentoring, counseling, and leadership programs within and between departments could be accelerated to eliminate horizontal sources of bullying. Workers could be given better resources and motivation to deal with stressors and adapt to the organizational climate. Hospital workers at all levels should be educated to have zero tolerance of bullying behavior and report any negative acts encountered at any time.

Limitations of the current study should be acknowledged. The cross-sectional nature of this study could not establish causal relationships. Although the measurement tool (NAQ-r) has been validated, it may have been susceptible to social desirability bias as a self-report measure, compounded by the probable acceptability of Hofstede's theorem, which may have resulted in an underestimation of bullying prevalence. The relatively small sample from a single center, coupled with the nonrepresentative demographics of the study population (such as the majority being women), and the use of nonprobability sampling may limit the generalizability of the study findings, and thus extrapolation of the findings to a nationally representative estimate could not be established. As observed in the study results, certain observations at the univariate and multivariate levels reflected wide CI gaps, thus implying that the accuracy of the effect size (ORs), although significant, may not have been wholly accurate. The CI reflected that the sample size was not adequate to determine associations for each variable. However, it should be noted that sample-size calculation for this study was not performed to find associations for a single observation alone, but involved other factors too, as bullying is a vast subject that includes many influences, eg. sociodemographics, organizational structure, work characteristics, environment, and individual behavior.

\section{Conclusion}

The prevalence of bullying among hospital workers according to the operational definition applied to the NAQ-r in this sample was $11.2 \%$, while self-labeled bullying accounted for $1.7 \%$. Common perpetrators were superiors or supervisors from other departments and colleagues. While factors associated with bullying in the univariate analysis were workers in the younger groups, those with less experience, not being involved in patient care, and working $<40$ hours per week. The core predictors yielded through the final regression model were that causes of bullying in this health-care institution were most likely associated with workers' experience and service orientation. It could be postulated that the bullying phenomenon may prevail in the current unstable economic environment, along with the escalated burden of health-care organizations' service delivery, as the literature has identified that such negative behavior may be catalyzed as a reflection of organizational restructuring or change, accompanied by budget and resource cuts. ${ }^{63}$ Given such factors, it would be wise for hospital directors and managers to identify groups or individuals vulnerable to bullying in the workplace to instigate appropriate coping mechanisms in the quest to prevent such negative behavior. While this study has identified potential factors associated with workplace bullying in a health-care organization, future studies with larger samples or multicenter studies that involve both public and private hospitals in Malaysia should be conducted to understand the overall situation of workplace bullying in this highly challenging industry, a crucial workforce in the nation's health-care needs. Outcome research could be conducted extensively, eg. identifying correlations between bullying and sickness absence among health-care workers. Such correlations may be crucial, as positive correlations may greatly impact routine healthservice delivery meeting client demand and needs.

\section{Consent for Publication}

Not applicable.

\section{Author Contributions}

All authors made substantial contributions to conception and design, acquisition of data, or analysis and interpretation of data, took part in drafting the article or revising it critically for important intellectual content, agreed to submit to the current 
journal, gave final approval to the version to be published, and agree to be accountable for all aspects of the work.

\section{Funding}

There is no funding to report.

\section{Disclosure}

The authors report no conflicts of interest for this work.

\section{References}

1. Leymann H. Mobbing and psychological terror at workplaces. Violence Vict. 1990;5:119-126. doi:10.1891/0886-6708.5.2.119

2. Cassitto MG, Fattorini E, Gilioli R, Gonik V, Fingerhut MA, KortumMargot EG. Raising awareness of psychological harassment at work. In: Gilioli R, Fingerhut MA, Kortum-Margot E, editors. Protecting Workers' Health Series. Geneva, Switzerland: World Health Organization; 2003.

3. Nielsen MB, Skogstad A, Matthiesen SB, et al. Prevalence of workplace bullying in Norway: comparisons across time and estimation methods. European $J$ Work Organizational Psychology. 2009;18:81-101. doi:10.1080/13594320801969707

4. Olweus D. Aggression in Schools: Bullies and Whipping Boys. Oxford, UK: Hemisphere; 1978.

5. Hurley J, Hutchinson M, Bradbury J, Browne G. Nexus between preventive policy inadequacies, workplace bullying, and mental health: qualitative findings from the experiences of Australian public sector employees. Int J Mental Health Nurs. 2016;25(1):12-18. doi:10.1111/inm. 12190

6. Einarsen S, Nielsen MB. Workplace bullying as an antecedent of mental health problems: A five-year prospective and representative study. Int Arch Occup Environ Health. 2015;88:131-142. doi:10.10 07/s00420-014-0944-7

7. Gupta R, Bakhshi A, Einarsen S. Investigating workplace bullying in India: psychometric properties, validity, and cutoff scores of negative acts questionnaire-revised. SAGE Open. 2017;1-12.

8. Carter M, Thompson N, Crampton P, et al. Workplace bullying in the UK NHS: a questionnaire and interview study on prevalence, impact and barriers to reporting. BMJ Open. 2013;3:e002628. doi:10.1136/ bmjopen-2013-002628

9. Chatziioannidis I, Bascialla FG, Chatzivalsama P, Vouzas F, Mitsiakos G. Prevalence, causes and mental health impact of workplace bullying in the neonatal intensive care unit environment. $B M J$ Open. 2018;8:e018766. doi:10.1136/bmjopen-2017-018766

10. Jamieson J, Mitchell R, Le Fevre J, Perry A. Bullying and harassment of trainees: an unspoken emergency? Emerg Med Australas. 2015;27:464-467. doi:10.1111/1742-6723.12465

11. Hoel H, Salin D. Organisational antecedents of workplace bullying. In: Einarsen S, Hoel H, Zapf D, Cooper C, editors. Bullying and Emotional Abuse in the Workplace: International Perspectives in Research and Practice. London: Taylor \& Francis; 2003.

12. Matthiesen SB, Einarsen S. Bullying in the workplace: definition, prevalence, antecedents and consequences. Int J Org Theory Behav. 2010;13:202.

13. Bradley V, Liddle S, Shaw R, et al. Sticks and stones: investigating rude, dismissive and aggressive communication between doctors. Clin Med. 2015;15:541-545. doi:10.7861/clinmedicine.15-6-541

14. Matthiessen SB, Raknes BI, Rokkum O. Mobbing paarbeidsplassen. Tidskrift for Norsk Psykologforening. 1989;26:761-774.

15. Quine L. Workplace bullying in NHS community trust: staff questionnaire survey. BMJ. 1999;318:228-232. doi:10.1136/bmj.318.71 78.228
16. Frank E, McMurray JE, Linzer M, Elon L. Career satisfaction of US women physicians: results from the women physicians' health study. Arch Intern Med. 1999;159:1417-1426. doi:10.1001/archinte.159. 13.1417

17. Paice E, Smith D. Bullying of trainee doctors is a patient safety issue. Clin Teach. 2009;6:13-17. doi:10.1111/j.1743-498X.2008.00251.x

18. Mojoyinola JK. Effects of job stress on health, personal and work behaviour of nurses in public hospitals in Ibadan Metropolis, Nigeria. Ethno-Med. 2008;2:143-148. doi:10.1080/09735070.2008.11886326

19. Giga SI, Hoel H, Lewis D. The costs of workplace bullying. Univ Manchester Institute Sci Technol. 2008.

20. Rodwell J, Demir D, Parris M, Steane P, Noblet A. The impact of bullying on health care administration staff: reduced commitment beyond the influences of negative affectivity. Health Care Manage Rev. 2012;37:329-338. doi:10.1097/HMR.0b013e31823dc2ec

21. Ariza-Montes A, Muniz NM, Montero-Simo MJ, Araque-Padilla RA. Workplace bullying among healthcare workers. Int $J$ Environ Res Public Health. 2013;10:3121-3139. doi:10.3390/ijerph10083121

22. Feijo FR, Debora DG, Neil P, Anaclaudia GF. Risk factors for workplace bullying: a systematic review. Int J Environ Res Public Health. 2019;16:1945. doi:10.3390/ijerph16111945

23. Paull M, Omari M. Workplace abuse, incivility and bullying: the challenge of translational research. In: Omari M, Paull M, editors. Workplace Abuse, Incivility and Bullying: Methodological and Cultural Perspectives. Abingdon, UK: Routledge; 2018:208-214.

24. Chan CMH, Wong JE, Yeap LLL, Wee LH, Jamil NA, Nantha YS. Workplace bullying and psychological distress of employees across socioeconomic strata: a cross-sectional study. BMC Public Health. 2019;19(S4):608. doi:10.1186/s12889-019-6859-1

25. Mokhtar D. Coping with workplace bullying among front line employees: a cross-sectional study. Int J Psychosocial Rehabilitation. 2020;24 (4):4238-4251. doi:10.37200/IJPR/V24I4/PR201532

26. Halim HAM, Halim FW, Khairuddin R. Does personality influence workplace bullying and lead to depression among nurses? Jurnal Pengurusan. 2018;53:16.

27. Mokhtar D, Adnan HA, Roshaizad NA. The correlates of workplace bullying on employees' health and well-being among frontline employees. Jurnal Psikologi Malaysia. 2018;32:88-101.

28. Samsudin EZ, Isahak M, Rampal S, Rosnah I, Zakaria MI. Organisational antecedents of workplace victimisation: the role of organisational climate, culture, leadership, support, and justice in predicting junior doctors' exposure to bullying at work. Int $J$ Health Planning Management. 2020;35(1):346-367. doi:10.1002/hpm.2926

29. Fanggy TS, Brian CI, Kashif H. The consequence of Malaysian national culture values on hotel branding. Procedia - Social Behavioral Sciences. 2014;144:91-101. doi:10.1016/j.sbspro.2014.07.277

30. Kish L. Survey Sampling. New York: John Wiley and Sons, Inc; 1965:78-94.

31. Eurofound. Fifth European Working Conditions Survey. Luxembourg: Publications Office of the European Union; 2012. doi:10.2806/34660

32. Naing L, Winn T, Rusli BN. Practical issues in calculating the sample size for prevalence studies. Arch Orofac Sci. 2006;1:9-14.

33. Norton P, Costa V, Teixeira J, et al. Prevalence and determinants of bullying among health care workers in Portugal. Workplace Health Saf. 2017;65:188-196. doi:10.1177/2165079916666545

34. Einarsen S, Raknes BI, Matthiesen SB. Mobbing Og Harde Personkonflicter. [Harassment and Serious Interpersonal Conflicts at Work]. Bergen, Norway: Sigma Forlag; 1994.

35. Jiminez BM, Munoz AR, Gamarra MM, Herrer MG. Assessing workplace bullying: spanish validation of a reduced version of the negative acts questionnaire. Span J Psychol. 2007;10:449-457. doi:10.1017/S1138741600006715

36. Makarem NN, Tavitian El-madjian LR, Brome D, Hamadeh GN, Einarsen S. Assessment of workplace bullying: reliability and validity of an arabic version of the negative acts questionnaire revised (NAQ-r). BMJ Open. 2018;8:e024009. doi:10.1136/bmjopen-2018-024009 
37. Yahaya A, Ing TC, Lee GM, et al. The impact of workplace bullying on work performance. Arch Sci. 2012;65:18-28.

38. Chambers CNL, Frampton CMA, McKee M, Barclay M. 'It feels like being trapped in an abusive relationship': bullying prevalence and consequences in the New Zealand senior medical workforce: a crosssectional study. BMJ Open. 2018;8:e020158. doi:10.1136/bmjopen2017-020158

39. Mikkelsen EG, Einarsen S. Bullying in Danish work-life: prevalence and health correlates. Eur $J$ Work Organizational Psychol. 2001;10:393-413. doi:10.1080/13594320143000816

40. Skogstad A, Matthiesen SB, Hellesoy OH. Hjelpepleiernes Arbeidsmiljokvalitet. En Undersokelse Av Arbeidsmiljo, Helse Og Trivsel Blant Hjelpepleierne I Hordaland. Bergen: University of Bergen; 1990.

41. Niedl K. Mobbing/Bullying Am Arbeitsplatz. Munich: Rainer Hampp; 1995.

42. Einarsen S, Skogstad A. Bullying at work: epidemiological findings in public and private organizations. European J Work Organizational Psychology. 1996;5:185-201. doi:10.1080/13594329608414854

43. Kauppinen T, Aaltonen M, Lehtinen S. Work and Health in Finland. Helsinki: Finnish Institute of Occupational Health; 1997.

44. Kivimaki M, Elovainio M, Vahtera J. Workplace bullying and sickness absence in hospital staff. Occup Environ Med. 2000;57:656-660. doi:10.1136/oem.57.10.656

45. Alkorashy HAE, Al-Moalad FB. Workplace violence against nursing staff in a Saudi university hospital. Int Nurs Rev. 2016;63:226-232.

46. Bairy KL, Thirumalaikolundusubramanian P, Sivagnanam G, Saraswathi S, Sachidananda A, Shalini A. Bullying among trainee doctors in Southern India: a questionnaire study. $J$ Postgrad Med. 2007;53:87-90. doi:10.4103/0022-3859.32206

47. Kamchuchat C, Chongsuvivatwong V, Oncheunjit S, Yip TW, Sangthong R. Workplace violence directed at nursing staff at a general hospital in Southern Thailand. $J$ Occup Health. 2008;50:201-207. doi:10.1539/joh.O7001

48. Hua YJ, Dai JM, Gao JL, Lu XY, Liu JY, Fu H. Association between psychosocial work environment and workplace bullying among office workers. Zhonghua Lao Dong Wei Sheng Zhi Ye Bing Za Zhi. 2016;34:262-266.

49. Yokoyama M, Suzuki M, Yukari T, Igarashi A, Noguchi-Watanabe M, Yamamoto-Mitani N. Workplace bullying among nurses and their related factors in Japan: a cross-sectional survey. J Clin Nurs. 2016;25:2478-2488. doi:10.1111/jocn.13270

50. Hogh A, Conway PM, Mikkelsen EG. Prevalence and risk factors for workplace bullying. In: Sturmey P editor. The Wiley Handbook of Violence and Aggression. John Wiley \& Sons Ltd;2017. doi:10.1002/ 9781119057574.whbva108

51. O'Moore M, Lynch J, Niamh ND. The rates and relative risks of workplace bullying in Ireland, a country of high economic growth Int J Management Decision Making. 2003;4:82-95. doi:10.1504/ IJMDM.2003.002490
52. Nielsen MB, Hetland J, Matthiesen SB, Einarsen S. Longitudinal relationships between workplace bullying and psychological distress. Scand J Work, Environ Health. 2012;38:38-46. doi:10. 5271/sjweh. 3178

53. Samnani AK, Singh P, Ezzedeen S. Workplace bullying and employee performance: an attributional model. Organizational Psychol Rev. 2013;3:337359.

54. Galanaki E, Papalexandris N. Measuring workplace bullying in organizations. Int J Human Resource Management. 2013;24: 2107-2130. doi:10.1080/09585192.2012.725084

55. Hofstede G. Culture's Consequences: International Differences in Work-Related Values. Thousand Oaks: Sage; 1980.

56. Kwan SSM, Tuckey MR, Dollard MF. The Malaysian Workplace Bullying Index (MWBI): A new measure of workplace bullying in Eastern countries. PLoS One. 2020;15:e223235. doi:10.1371/journal.pone. 0223235

57. Vessey JA, DeMarco RF, Bullying DR. Harassment and horizontal violence in the nursing workforce. Annu Rev Nurs Res. 2010;28:133-157. doi:10.1891/0739-6686.28.133

58. Serafin LI, Czarkowska-Paczek B. Prevalence of bullying in the nursing workplace and determinant factors: a nationwide cross-sectional Polish study survey. BMJ Open. 2019;9:e033819. doi:10.1136/bmjopen-2019-033819

59. Laschinger SHK, Nosko A. Exposure to workplace bullying and post-traumatic stress disorder symptomology: the role of protective psychological resources. J Nurs Manag. 2015;23:252-262. doi:10.11 11/jonm.12122

60. Yang LQ, Spector PE, Chang C-HD, Gallant-Roman M, Powell J. Psychosocial precursors and physical consequences of workplace violence towards nurses: a longitudinal examination with naturally occurring groups in hospital settings. Int $J$ Nurs Stud. 2012;49:1091-1102. doi:10.1016/j.ijnurstu.2012.03.006

61. Oh H, Uhm DC, Yoon YJ. Factors affecting workplace bullying and lateral violence among clinical nurses in Korea: descriptive study. $J$ Nurs Manag. 2016;24:327-335.

62. Zapf D, Escartin J, Einarsen S, Hoel H, Vartia M. Empirical findings on prevalence and risk groups of bullying in the workplace. In: Einarsen S, Hoel H, Zapf D, Cooper CL, editors. Bullying and Harassment in the Workplace: Developments in Theory, Research, and Practice. Boca Raton, FL: CRC Press; 2011:75-105.

63. Hoel H, Cooper C. Destructive Conflict and Bullying at Work. Manchester: UMIST; 2000.
Risk Management and Healthcare Policy

\section{Publish your work in this journal}

Risk Management and Healthcare Policy is an international, peerreviewed, open access journal focusing on all aspects of public health, policy, and preventative measures to promote good health and improve morbidity and mortality in the population. The journal welcomes submitted papers covering original research, basic science, clinical \& epidemiological studies, reviews and evaluations, guidelines, expert opinion and commentary, case reports and extended reports. The manuscript management system is completely online and includes a very quick and fair peer-review system, which is all easy to use. Visit http://www.dovepress.com/testimonials.php to read real quotes from published authors. 